\title{
Citizens' Attitudes towards Electronic Identification in a Public E-Service Context - An Essential Perspective in the eID Development Process
}

\author{
Karin Axelsson and Ulf Melin \\ Department of Management and Engineering, \\ Linköping University, SE-581 83 Linköping, Sweden
}

\begin{abstract}
This article addresses the development of electronic identification (eID) for public e-services and reports from an empirical study of young Swedish university students' attitudes towards eID. A public e-service at the Swedish Board for Study Support which demanded secure electronic identification was focused. Our findings from three focus groups show that usability and security are two main themes that the respondents found to be important in order to trust eID and e-services. This example of how citizens' attitudes towards eID can be explored in focus groups is related to an on-going national development process of a new eID solution on a strategic and artifact level. In this process no citizens are participating or involved so far. Potential risks with neglecting citizen attitudes in such processes, in a longer perspective, are decreased usage of public e-services and lack of trust in e-government. This article shows that citizens' attitudes can serve as important additional input to the development of eID solutions that supports successful e-government.
\end{abstract}

Keywords: Electronic Identification, Citizens’ Attitudes, Focus Groups, Public E-service, Trust.

\section{$1 \quad$ Introduction}

The use of public e-services is increasing in most countries, as an important part of egovernment. More advanced, integrated public e-services are introduced, compared to early years' cataloguing e-services [22]. Complex e-services do often require secure solutions for electronic identification and signing of documents [cf. 30]. There are many on-going efforts to develop electronic IDs (eID) that are equally secure and easy to use, both on national level [35] and in international projects. The European Commission conducted a survey in 2007 indicating that a majority (28 out of 32 ) of the member countries use or plan to use an eID scheme [12]. Some countries have signed agreements on mutual recognition, but eID systems differ between member states and inter-operability across borders was almost non-existent at the time of the survey [ibid.]. In EU this situation has been addressed within the STORK project (Secure identity across borders linked) where a European eID inter-operability platform has been established in order to enable citizens and businesses to use their national eIDs in any participant member state for use of public e-services [ibid.]. 
In Sweden, which is the national context of the empirical study in this article, a coordinating function responsible for the development of Sweden's future eID solution has recently been established. The commission of this e-identification board is to define technical requirements and enable government agencies' and municipalities' access to eID solutions. The goal of this effort is to provide eIDs to citizens and businesses that are easily accessible and possible to use together with all public e-services. This should also enhance competition between service providers and improve conditions for developing new methods of electronic identification and signing of documents [35].

As these examples show, there is a lot of work going on in the field of eID development and implementation. Even though the e-government area nowadays is surrounded by statements of the importance to be citizen-oriented and user-focused [e.g. $5 ; 18 ; 24 ; 26 ; 36]$, we do however not identify the same user centeredness when it comes to eID development. The issue's complicated matter seems to imply a focus on infrastructures, standardization, and involved governmental actors' power relations at the expense of citizens. eID's technical nature together with security and privacy issues are instead put in foreground. The ambition to reach consensus among all involved public organizations seems to be demanding enough, without analyzing citizens' attitudes as users of eID. In one sense, eID can be viewed as a technical aspect of e-services. No one choses to use an eID without a purpose; i.e. an eID is always used in conjunction with an e-service, and as such it is an important prerequisite for an e-service. On the other hand, for the common e-service users it can be difficult, and not even necessary, to separate the eID from the e-service. The link between an e-service and the eID is also an aspect not explicitly addressed in the literature. The eID in general has received relatively little attention in non-technical research [33] and is identified as an urgent research theme [17]. To put it in other words, the material dimension of the eID has, so far, received more attention than the social and organizational dimension of it [cf. 27]. The users' experience of the eID might influence their opinions of the e-service and vice versa, as well as the service provider, largely. This makes us argue that citizens' attitudes towards eID are crucial to understand, from a theoretical and practical point of view, in order to increase successful public e-service and e-government development, implementation, and use.

The purpose of this article is, thus, to highlight the importance of addressing and exploring a selected group of citizens' attitudes when developing eID solutions within a public e-service context. We report from an empirical study of young Swedish university students' attitudes towards eID when using an e-service at the Swedish Board for Study Support. Three focus groups were conducted with students who were asked to use a public e-service which demanded secure electronic identification. After having conducted the assigned tasks the students' attitudes were discussed in the focus group. By using this example we aim to show that a thorough understanding of how a certain crucial target group (in this case students who finance their university studies with national study loans) apprehends the use of electronic identification is vital in this kind of national development process. 
After this introduction, the article is organized in the following way: In Section Two we describe the theoretical background of electronic identification as well as citizen participation and involvement in e-government projects, followed by the research approach and the focus group design in Section Three. In Section Four we present and analyze our empirical findings. The article is concluded in Section Five, together with some statements about further research.

\section{Theoretical Background}

In this section of the article we discuss core concepts from the fields of electronic identification and citizen involvement and participation in e-government projects.

\subsection{Electronic Identification}

When technical systems, with social and material dimensions [27], such as e-services, are developed to avoid risks and problems in society, new risks might evolve simultaneously [11]. The development of eID solutions is an example of this kind of process that deals with certain problems, but also creates new requirements of security and trust in the systems. In Sweden several governmental inquiries have questioned both the technical infrastructure and the business model that today's eID solution builds upon. The investigations point at several weaknesses; e.g. technical complexity, a complicated business and pricing model, as well as lack of transparency, flexibility, user interface standards, and a long-term perspective. Additionally, user related problems are also reported regarding acquisition, usage and updating of eIDs. It is, for example, not possible to use eIDs on public computers since the eID is connected to certificates and security applications on a certain computer. People without permanent residence in Sweden cannot easily get an eID which might be seen as a democracy problem. People who need to use eID in their professional work have to use their personal eID as all eIDs are based on a person's social security number. [34] Altogether, there is a fear that the legitimacy of safe public e-service provision might be threatened by these weaknesses. Since the agreement with the present eID solution providers soon is about to be renewed, a development process that should result in a new eID solution avoiding the above mentioned problems has been initiated.

The process is organized by the Swedish e-identification board, mentioned in the introduction. The process is on-going and has so far engaged public sector in many ways; both directly as participants in the process and as reviewers and critics of the suggested outcome. A public investigation has been conducted, a hearing has been held, and many public actors have been involved in different ways [35]. In one sense this process is very inclusive and open minded as it strives to listen to and involve as many stakeholders as possible. One group that is left outside the process is, on the other hand, the citizens. 


\subsection{Citizen Involvement and Participation in E-Government Projects}

In an e-government context, public e-services are developed for "all citizens", thus, an inclusive ambition seems feasible [e.g. 2; 4; 31]. Understanding the needs, usage situation, requirements and challenges of future users is necessary in order to develop public e-services that will be frequently used. Governments cannot actively stimulate or even force usage in the same way as a private organization can order employees to use a certain IT system. This situation makes it even more delicate to develop public e-services. Commonly used methods for user participation, such as participating in the project group, in focus groups (as described below) or test groups, might be useful in the e-government context as well. But since such representatives for citizen groups always will be extremely marginal in relation to all possible users in a target group, we also need other methods to involve citizens [5].

In e-government policies and strategies there has often been a strong rhetorical emphasis on the citizen perspective. In many governments' national strategic action plans for their e-government agenda, citizen aspects, as a part of "customer orientation", are distinctly put forth. The ambition to ease citizens' authority contacts, provide better public services, make governmental internal work processes more efficient and ease administrative burden, and increase possibilities to participate in democratic processes (e-participation) are a few examples of intended citizen benefits to be identified in strategic governmental intentions and documents [e.g. 8; 36; 39]. At the same time, lack of citizen participation and involvement is common in many egovernment projects and by several researchers explained as a reason for unsuccessful project results [e.g. 18; 29]. Citizen participation can contribute to e-services that are usable for the citizen and meet an experienced need or solve citizens' problems [15]. These e-services also have potential to be trusted and perceived as secure, as trust in technology and administration often goes hand in hand [6]. Altogether, previous studies on the importance of citizen participation [5] imply that the development process of eID should not be seen as an exception. Citizens' attitudes, thus, need to be considered when developing eID solutions as a part of public e-service use and egovernment development and implementation.

\section{Research Approach}

The overall research design in this study is qualitative and interpretive [41] and based on three interactive focus groups. Focus groups have a long history as a data collection method in the marketing field [13]. Over the years focus groups have become an instrument in the public society to hear "the people's voice". Focus groups are also used as a data collection method by researchers, mainly in social sciences [40]. Recently, focus groups have been used as a method in critical social information systems (IS) research [37]. Morgan [25] describes focus groups as group interviews. A moderator guides the group when discussing decided issues by posing questions (in our case open ended questions together with questions oriented towards particular aspects of the eID solution) that have been formulated in advance. A focus group is always created with a specific purpose; a knowledge gap that the focus group is 
supposed to fulfill. Focus groups are a feasible method to gather knowledge and enquiries from different individuals [ibid.]. Different persons possess pieces of knowledge about a certain matter and when these pieces are brought together, shared and discussed the total amount of knowledge increases. When organizing and performing a focus group it is important to be able to declare what the group is supposed to produce; the expected outcome.

The moderator who coordinates the focus group must try to facilitate that everyone participates and that no one dominates the group. The atmosphere should be friendly to encourage everybody to contribute to the discussion in order to fulfill the underlying purpose of the focus group. The moderator is not supposed to insert his or her own opinions into the discussion [20]; instead the moderator should ask generative questions to the group. Morgan [25] argues that the focus group can be either homogenous or heterogeneous. This implies that the participants can either be gathered so that they are similar or different regarding certain matters; for example, gender, age, education, and life situation. There are advantages with groups of people knowing each other as well as with groups of strangers. Individuals view issues from different perspectives and focus groups are, thus, a suitable method to use in order to understand how different views are constructed and expressed [19]. Focus groups thereby provide a profound discussion in a certain matter. This is in line with Powell and Single [28] who define a focus group as 'a group of individuals selected and assembled by researchers to discuss and comment on, from personal experience, the topic that is the subject of the research' [p 499].

Stahl et al. [37] note that focus groups, despite the long history in many fields, still is not an often used data collection method in IS research. However, focus groups have been used in several e-government projects to gather citizens' opinions of eservices $[9 ; 10]$ before and during e-service development processes [e.g. 1; 23]. Focus groups have also been characterized as a suitable and beneficial research method when conducting e-government studies [3]. In this study we follow a proposed phase model for focus groups in e-government development and implementation projects, which is further described below.

\subsection{Focus Group Design and Performance}

Axelsson and Melin [4] propose a phase model to guide the performance of focus groups. The phases are (1) introduction, (2) open discussion - brainstorming, (3) discussion from user scenarios or use of e-services, (4) concept based discussion, and (5) evaluation. In this study the Swedish Board for Study Support was chosen as the empirical case. The Swedish Board for Study Support is an agency which early launched public e-services that demanded secure electronic identification and was, thus, suitable for this study. The Swedish Board for Study Support's main, and crucial, target group is students who finance their studies by national study loans. Therefore we recruited in total 16 university students from a Swedish university as focus group participants. Three focus groups were arranged; one focus group with six students from mixed educational programs ("Mixed"), one focus group with six students from information systems studies ("IS"), and one focus group with four 
students from culture studies ("Cultural"). By doing this we aimed for both heterogeneous and homogenous groups regarding educational background, as discussed by Morgan [25]. The focus groups also differed regarding gender, which year of university studies the student was in, and what kind of computer and certificate the student used. Both soft certificate ("Soft") (downloaded to a certain computer) and hardware based certificates ("Hard") (a smartcard with the certificate) were used, as well as PC compatible computers ("PC") and Apple Macintosh ("Mac"). Below in table 1, the focus group participants are described.

Table 1. Three Focus Groups

\begin{tabular}{l|l|c|c|l|l|l} 
Focus group & Gender & Respondent & Year & Education & Certificate & Computer \\
\hline \multirow{4}{*}{ Mixed } & Male & M-1 & 5 & Industrial economics & Soft & PC \\
& Male & M-2 & 1 & Industrial economics & Soft & PC \\
& Female & M-3 & 1 & Information systems & Soft & PC \\
& Female & M-4 & 4 & MBA & Hard & MaC \\
& Male & M-5 & 2 & Information systems & Hard & PC \\
& Male & M-6 & 1 & Industrial economics & Soft & PC \\
\hline \multirow{5}{*}{ IS } & Male & IS-1 & 4 & Information systems & Soft & Mac \\
& Male & IS-2 & 4 & Information systems & Soft & PC \\
& Male & IS-3 & 4 & Information systems & Soft & PC \\
& Male & IS-4 & 4 & Information systems & Soft & Mac \\
& Male & IS-5 & 4 & Information systems & Soft & Mac \\
& Female & IS-6 & 4 & Information systems & Soft & PC \\
\hline \multirow{5}{*}{ Cultural } & Male & C-1 & 3 & Cultural studies & Soft & PC \\
& Male & C-2 & 1 & Cultural studies & Hard & PC \\
& Female & C-3 & 4 & Cultural studies & Soft & PC \\
& Female & C-4 & 4 & Cultural studies & Soft & PC
\end{tabular}

We followed the advice to let two moderators lead the focus group [4]. One of them could then be active and provide the discussion by posing questions while the other documented and observed the situation. The focus groups were initiated by the two moderators who introduced the purpose of the focus group. All participants had a client relation to the Swedish Board for Study Support; i.e. they had taken national study loans. They had also access to an eID and had previously used some e-services at the Swedish Board for Study Support's website. This implies that the participants were not totally novel e-service and eID users. After the introduction and an open discussion about the electronic identification topic, the participants were asked to use an e-service at the website (www.csn.se) to perform two tasks; 1) use their eID to login and calculate the repayment, and 2) suppose that they have forgotten their eID password and had to solve this problem. When all participants had performed these two tasks the moderators led the discussion based on open questions. The purpose of this discussion was to find out the participants' opinions about the tasks they had completed; for example, if the tasks were easy, if they encountered any problems, but also how they thought about security aspects when they used their eIDs and the 
e-service. Questions were asked both about the present solution for eID and wishes for the future. The focus groups were concluded with an evaluation where the process was examined in order to find aspects that could be improved in next focus group or issues that had not been covered in the discussion.

The focus group documentation was then analyzed in an interpretative way [41] in order categorize data and identify patterns that would provide us with further understanding of young citizens' attitudes towards electronic identification. This qualitative, empirically grounded analysis resulted in two major themes of the respondents' attitudes; usability of eID and security of eID. These themes are discussed in the next section.

\section{$4 \quad$ Analysis of Focus Groups Statements}

In this section we discuss some inductive statements from the focus group participants in order to explore young citizens' attitudes towards their use of eID. As the analysis of the empirical data indicates two major themes; usability and security, the statements are structured according to these themes.

The focus group participants brought their own laptops (PC or Mac) to the meeting together with their soft or hardware based certificate for eID. They were asked to conduct the tasks in the web browser they usually use. Both soft and hardware based certificates have certain operative system (OS) requirements that have to be met. This implies that the user of a certain certificate has to install an approved OS and web browser version before use. Soft certificates are downloaded to the computer or to an USB memory stick. Soft certificates also require a security application on the computer, but can then be used without any other device. Hardware based certificates are placed on a smartcard which is put in a certain smartcard reader connected to the computer. The heterogeneity of today's eID solutions was illustrated in the focus groups as the above mentioned platform dependencies were present and discussed.

\subsection{Usability of eID}

The focus group participants were asked to solve the task to get a new password for their eID. Depending on what eID solution they use, they encountered different usability related challenges and problems. The participants did not immediately know how to solve the task, but most participants found out that they had to contact their bank as the bank is certificate provider. The common opinion was that this was unnecessarily cumbersome. Several participants argued that it was not worth the effort to get a new password instead of downloading a new certificate: "There are so few things I use eID for, so the effort I spend on downloading the certificate and put it on a USB stick that I bring with me, does not match the need. It's easier to just download a new one next time." [IS-3]

The students use their eID rather seldom, which makes them argue that they could accept some usability inconveniences. On the other hand, they seem to find their eID solutions usable. As one of the respondents [IS-4] said, he would not use it if it had 
severe usability problems. He argued that usability is much more important than security in this case. Another respondent agreed and continued: "If it isn't useful, I might as well choose to use paper forms and a pen instead." [C-3]

One respondent [M-6] thought that the fact that he has to download a new certificate when he changes computer makes the portability and the usability suffer. Another respondent [M-2] assumed that this must be an even larger problem for novice Internet users, which others agreed upon: "We are used to download things. What about elderly people who might not understand why they have to download security applications and certificates?" [M-3]

Differences regarding how citizens of certain ages regard eID and the use of public e-services were also discussed during the focus groups. As we have only studied young and well-educated citizens (i.e. university students), most of them technology positive, this view might of course be biased. However, the respondents agreed that their generation is used to information technology and e-services, but also puts high expectations on their usability: "We belong to the Wikipedia generation - a click and then we expect everything to be done." [IS-1]

Altogether the focus group discussions illustrate that even though the general impression is that the present eID solutions are rather usable, there are some aspects that influence the opinions about usability of eID. The frequency of eID use is put forth as one aspect together with how familiar a person is with the Internet and eservices in general terms. These aspects seem to affect the attitude towards the use of eID. Flexibility in the usage situation is partly dependent on which kind of certificate a user has, and this is also emphasized as an important aspect of the usability impression.

\subsection{Security of eID}

The other theme present in the focus group discussions is security, which of course is an obvious dimension of electronic identification. One respondent said that she finds her eID to be safe, which is important for her: "If I had not felt it was safe, I would not have used it." [IS-6]

One of the respondents [IS-1] argued that security in present eID solutions is rather low, that is at least his impression of it. He said that since he downloads a new certificate each time he uses the eID, due to forgotten passwords, he gets the feeling that it is unsecure. Another respondent [IS-3] continued this line of thinking and said that the security level is so high that the usability suffers and that, instead, decreases security, when people act as this respondent [IS-1] does.

The focus groups with students from mixed educations and information systems studies mostly agreed that the use of eID had several advantages compared to the use of paper-based forms. The speed and the sense of security when getting a receipt immediately after signing a document were regarded as advantages compared to manual handling. In the third focus group, consisting of students in cultural studies, the opinion that traditionally signing feels more secure was instead dominating. This notion was also mentioned by a respondent in one of the other focus groups: "I can 'feel the paper' when I'm signing a document in a traditional way, instead of using 
the Internet. I think people appreciate that feeling. That is probably the main reason for people not using e-services." [IS-4]

However, none of the three focus groups seemed seriously worried about security issues when using eID. The fact that there are no financial transactions or sensitive personal information in the tested e-service appears to be decisive. The students use eID mainly in their contacts with the Swedish Board for Study Support and the Swedish Tax Agency. These agencies' e-services do concern financial matters (loans and taxes), but the students do not apprehend the eID use as directly influencing their finances. A respondent argued that there is no really harm if: "[...] someone would sign something in my name at the Swedish Board for Study Support.” [M-1]

This is an interesting opinion to relate to the on-going development processes of new eID solutions, as security is the main theme in these projects. An eID solution does of course have to be secure. The focus groups results do, however, illustrate that usability aspects are put forth as even more important to young citizens than security.

\section{$5 \quad$ Conclusions and Further Research}

Even though the findings from the focus groups indicate that young citizens regard usability as more important than security aspects when using eID, we also identified a relationship between usability and security in the data material. Both usability and security aspects are requested if the respondents should use the eID and, consequently, the e-service. When they regard the levels of both usability and security as satisfying they trust the electronic identification and signing process. The attitudes above concerning usability and security are, thus, linked to trust - a theme only briefly touched upon above in the focus group data. Trust is an important factor in all identification processes; both as a prerequisite and as an effect of identification. In fact, democracy depends in part on the trust in public institutions on a general level [21]. Therefore, trust is an essential issue also in e-government research and development. Several studies have explored the role of trust in different sectors.

Trust can be related to the potential of public e-services to improve government transparency, responsiveness, and accountability. Even with this potential, e-services will only be adopted if citizens deem them trustworthy [6]. Bélanger and Carter [ibid.] provide a model where they divide trust into institution-based trust (e.g. trust in the Internet, such as secure data transmission, as an essential part of e-government) and trust in the government agency providing the e-service. The latter highlights aspects such as organization and knowledge in the agency. Labels like "trust in the government" and "trust in the Internet" are also present [ibid.]. In the light of this model, usability aspects might be related to trust in the government while security aspects are vital for trust in the Internet. Understanding both these kinds of trust seems to be essential for development of successful eID solutions.

The perceived level of trust in the eID influenced whether the respondents in our study choose to use the e-service or not. If they cannot remember their password or find it too cumbersome to download a new certificate, they use another communication channel when interacting with the agency. This is an important aspect 
that goes against the view of eID development as a purely technical matter that does not have to comprise any user participation. One theoretical contribution of the study is thus that there is a need to focus both social and material dimensions of the artifact [27] in this case the eID. The eID obviously serves as an entrance to the e-service, which usability and security levels might discourage or encourage the citizen to go on and use the e-service. This is in a long-term perspective decisive for an agency's possibility to realize the potentials in using e-services as a part of e-government development.

The purpose of this article has been to highlight the importance of addressing and exploring a certain group of citizens' attitudes when developing eID solutions within a public e-service context. The three conducted focus groups have provided us with illustrations of how young citizens, in our case university students within different study programs, think about the usability and security of eID. Even though the small amount of respondents cannot tell us how general these attitudes are in a statistical sense, the very presence of attitudes of eID indicates that citizens should not be excluded from the development and the future implementation process. This also calls for further theoretical and practical investigations of perspectives and models, e.g. conceptual foundations of identity and e-identity [16]. This study contributes with an illustration of how attitudes gathered from the focus groups can be used as an early warning system providing decision makers, development project leaders, and others with indications of aspects and interpretations of the intended eID solutions in an eservice usage situation. Neglecting citizen attitudes cannot be done without risking that important opinions are disregarded. This might in a longer perspective lead to decreased usage of public e-services and lack of trust for e-government, as discussed above. We have shown a brief example of how citizens' attitudes can be caught. These attitudes can serve as important additional input to the development of eID solutions that supports successful e-government. A conclusion from this study is that citizen participation is important not only in public e-service development, but also when developing electronic identification solutions for e-services. This also calls for further conceptual and theoretical studies in the area.

It is has not been our ambition to give a comprehensive view of citizens' attitudes towards eID in this article, but our findings indicate that further citizen-oriented studies are necessary as complement in national and international development and implementation processes. Future contributions to conceptual development regarding e.g. the linkages between the eID and the e-service, and the general citizen orientation perspective in the e-government research field are also essential. A more systematic approach to explore different citizen groups' attitudes towards eID in an e-service context would be a feasible next step to take, also including groups with a different age structure, private vs. professional eID use, and public sector vs. private sector (e.g. e-business). Addressing trust [cf. 6] deeper in the eID context is another major issue for further research. eID can also be studied in relation to the concept of personal identity [cf. 7] and technology adoption and acceptance [38] in order to better understand the theoretical basis for electronic identification. The latter dimension can also be combined with a more explicit stakeholder perspective $[14 ; 32]$ in further research. The interface between the eID and the e-service used is also 
interesting to study more in depth, as well as the type of e-service offered (e.g. if sensitive or more confidential information is affected than in the present case) and its relation the eID. The fact that several providers of e-services and eID's are present makes the issue of trust and accountability even more delicate, not at least when breakdowns occur.

Acknowledgments. This study has been financed by the Swedish Civil Contingencies Agency. We are also thankful to Karl Eriksson and Tommy Talén, master students in information systems 2011, for their supportive work in the focus groups described above.

\section{References}

1. Albinsson, L., Lind, M., Forsgren, O., Ozan, H.: Turning the internet around - e-Me: The Students ideal e-Service, eChallenges (e*2006), Barcelona, Spain, October 25-27 (2006)

2. Anthopoulos, L.G., Siozos, P., Tsoukalas, I.A.: Applying participatory design and collaboration in digital public services for discovering and re-designing e-Government services. Government Information Quarterly 24(2), 353-376 (2007)

3. Axelsson, K., Melin, U.: Talking to, Not About, Citizens - Experiences of Focus Groups in Public E-Service Development. In: Wimmer, M.A., Scholl, J., Grönlund, Å. (eds.) EGOV 2007. LNCS, vol. 4656, pp. 179-190. Springer, Heidelberg (2007)

4. Axelsson, K., Melin, U.: Citizen Participation and Involvement in eGovernment Projects: An Emergent Framework. In: Wimmer, M.A., Scholl, H.J., Ferro, E. (eds.) EGOV 2008. LNCS, vol. 5184, pp. 207-218. Springer, Heidelberg (2008)

5. Axelsson, K., Melin, U., Lindgren, I.: Exploring the Importance of Citizen Participation and Involvement in E-government Projects - Practice, Incentives and Organization. Transforming Government: People, Process and Policy 4(4), 299-321 (2010)

6. Bélanger, F., Carter, L.: Trust and risk in e-government adoption. Journal of Strategic Information Systems 17(2), 165-176 (2008)

7. Beynon-Davies, P.: The Enactment of Personal Identity. In: Tuunainen, V., Nandhakumar, J., Rossi, M., Soliman, W. (eds.) Proceedings of the 19th European Conference on Information Systems, Helsinki, Finland (2011)

8. Building Britain's Digital Future. PM Gordon Brown's speech (March 22, 2010), http: / / www . labour. org.uk/gordon-browns-speech-on-buildingbritains-digital-future (March 22, 2010) (accessed November 02, 2011)

9. Cook, M.E.: What citizens want from e-government. Center for Technology in Government, New York, USA (2000)

10. Cullen, R., Hernon, P.: Wired for well-being: Citizens' response to e-government, A report presented to the E-government Unit of the State Services Commission, New Zealand (2004)

11. Czarniawska, B.: Organizing in the face of risk and threat. Edward Elgar, Northampton (2009)

12. European Commission. Secure Electronic Identity Across Europe, European Commission - Information Society and Media DG (November 2010)

13. Fern, E.F.: Advanced focus group research. Sage Publications, Thousand Oaks (2001) 
14. Flak, L.S., Rose, J.: Stakeholder governance: Adapting stakeholder theory to egovernment. Communications of the Association for Information Systems 16, 642-664 (2005)

15. Goldkuhl, G.: What Does it Mean to Serve the Citizen in E-Services? - Towards a Practical Theory Founded in Socio-Instrumental Pragmatism. International Journal of Public Information Systems 3, 135-159 (2007)

16. Halperin, R., Backhouse, J.: A roadmap for research on identity in the information society. Identity in the Information Society 1(1), 71-87 (2008)

17. Irani, Z., Elliman, T., Jackson, P.: Electronic transformation of government in the U.K.: a research agenda. European Journal of Information Systems 16(4), 327-335 (2007)

18. Jones, S., Hackney, R., Irani, Z.: Towards e-government transformation: conceptualising 'citizen engagement'. Transforming Government: People, Process and Policy 1(2), 145152 (2007)

19. Kitzinger, J., Barbour, R.S.: The challenge and promise of focus groups. In: Barbour, R.S., Kitzinger, J. (eds.) Developing Focus Group Research: Politics, Theory and Practice, pp. 1-20. Sage Publications, London (1999)

20. Krueger, R.A.: Moderating focus groups: Focus group kit 4. Sage Publications, Thousand Oaks (1998)

21. Lauer, T.W.: The risk of evoting. Electronic Journal of e-Government 2(3), 177-186 (2004)

22. Layne, K., Lee, J.: Developing Fully Functional E-government: A four-stage model. Government Information Quarterly 18(2), 122-136 (2001)

23. Lindblad-Gidlund, K., Nilsson, O.: Everyday communication home and school (echoes) A practical example of a public systems development from a citizen's perspective. In: Axelsson, K., Goldkuhl, G. (eds.) Proceedings of the International Workshop on Eservices in Public Administration, pp. 75-84 (2006)

24. Ministerial Declaration on eGovernment. Approved unanimously in Malmö, Sweden (November 18, 2009)

25. Morgan, D.: The focus group guidebook, vol. 1. Sage Publications Inc. (1998)

26. OECD. Focus on Citizens: Public Engagement for better Policy and Services, OECD Studies on Public Engagement (2009) ISBN 978-92-64-04886-7

27. Orlikowski, W.J., Scott, S.V.: Sociomateriality: Challenging the Separation of Technology, Work and Organization. The Academy of Management Annals 2, 433-474 (2008)

28. Powell, R.A., Single, H.M.: Focus groups. International Journal of Quality in Health Care 8(5), 499-504 (1996)

29. Reddick, C.G.: Citizen interaction with e-government: From the streets to servers? Government Information Quarterly 22(1), 38-57 (2005)

30. Rössler, T.: Giving an interoperable e - ID solution: Using foreign e - IDs in Austrian e - Government, Interoperability in electronic identity management. Computer Law \& Security Report 24(5), 447-453 (2008)

31. Schedler, K., Summermatter, L.: Customer orientation in electronic government: Motives and effects. Government Information Quarterly 24(2), 291-311 (2007)

32. Scholl, H.J.J.: Applying stakeholder theory to e-government: benefits and limits. In: 1st IFIP Conference on ECommerce, E-Business, and E-Government, Zürich, Switzerland (2001)

33. Seltsikas, P., O'Keefe, R.M.: Expectations and outcomes in electronic identity management: the role of trust and public value. European Journal of Information Systems 19(1), 93-103 (2010) 
34. SOU 2009:86. Strategi för myndigheternas arbete med e-förvaltning (2009) (in Swedish)

35. SOU 2010:104. E-legitimationsnämnden och Svensk e-legitimation (2010) (in Swedish)

36. SOU 2011:67. As simple as possible for as many as possible - The way to more effective eGovernment, Summary of report by the eGovernment Delegation, Swedish Government Inquiries (2011)

37. Stahl, B.C., Tremblay, M.C., LeRouge, C.M.: Focus groups and critical social IS research: how the choice of method can promote emancipation of respondents and researchers. European Journal of Information Systems 20(4), 378-394 (2011)

38. Titah, R., Barki, H.: E-Government Adoption and Acceptance: A Literature Review. International Journal of Electronic Government Research 2(3), 23-57 (2006)

39. The Danish E-government Strategy 2007-2010. Towards better digital service, increased efficiency and stronger collaboration, The Danish Government, LGDK and Danish Regions (2007)

40. Vaughn, S., Schumm, J.S., Sinagub, J.: Focus group interviews in education and psychology. Sage Publications, Thousand Oaks (1996)

41. Walsham, G.: Doing interpretive research. European Journal of Information Systems 15(3), 320-330 (2006) 